\title{
The establishment of evaluation index system and the empirical research on the financial activity ability of specialized farmer's cooperatives
}

\author{
Xiaozhong Song, Linbin Wang and Jing Zhao \\ Department of Accounting, Yan Shan University, Qinhuangdao 066004, China
}

Keywords: specialized farmers cooperatives, financial activity, evaluation.

\begin{abstract}
The current Chinese specialized farmers cooperatives' financial activity capacity is generally weak, this paper constructs an evaluation model of financial activity capacity using the factor analysis method and structural equation, then gives an empirical research based on field survey data of specialized farmers cooperatives in Suning county.
\end{abstract}

\section{Introduction}

Chinese specialized farmer's cooperatives encountered many problems in the process of vigorous development, especially problems about financial activities including financing difficulties, low efficiency of capital operation and irrationality of income distribution, which are in great need of being solved. And the key is to construct a financial activity capacity evaluation model on the basis of influencing factors, and make evaluation on specialized farmers cooperatives' financial activity capacity using the field survey data. In this way, Cooperatives of stakeholders can clear cooperatives' financial activity and make improvements, which has important significance to promote the smooth development of cooperatives.

\section{The Establishment of evaluation index system}

Financial activities ability owed by companies is the combination of unique knowledge and experience, including financing capacity, investment capacity and distribution capacity, etc.

Table 1 Financial activities ability evaluation indicator system

\begin{tabular}{ccc}
\hline Rule layer & Index layer & Index code \\
\hline \multirow{2}{*}{ Financing ability } & Basic ability & F1 \\
$\mathrm{F}$ & Development potential & F2 \\
& Support & F3 \\
Investment operation ability & Group size & O1 \\
$\mathrm{O}$ & Operating activities & O2 \\
& Investment in science and technology & O3 \\
& Membership benefits & O4 \\
Income distribution fits & Social influence & O5 \\
$\mathrm{D}$ & Decision-making process & D1 \\
& Implementation process & D2 \\
& Effect of distribution & D3 \\
\hline
\end{tabular}

The data used in the article is gained from a field survey on specialized farmer's cooperatives of Suning County in Hebei Cangzhou, for the reason that Suning cooperatives have great development in recent years. In this research, 66 cooperatives are surveyed through 200 copies of questionnaires, and 198 copies are taken back, among which 178 copies questionnaires are useful.

\section{Reliability analysis}

After standardizing the data processing and using SPSS18.0 to measure samples collected, the minimum value of $\alpha$ is 0.755 , meeting the requirements of the reliability and passing the reliability test, as is shown in Table 2. 
Table 2 a total of statistics of specialized farmers cooperatives' financial activities ability

\begin{tabular}{cccccc}
\hline $\begin{array}{c}\text { Indicator } \\
\text { s }\end{array}$ & $\begin{array}{c}\text { Deleted average } \\
\text { scale }\end{array}$ & $\begin{array}{c}\text { Deleted scale } \\
\text { variance }\end{array}$ & $\begin{array}{c}\text { correction of a total } \\
\text { correlation }\end{array}$ & $\begin{array}{c}\text { Deleted } \alpha \text { of the } \\
\text { item }\end{array}$ & $\alpha$ \\
\hline F1 & 4.767 & .905 & .708 & .913 & \\
F2 & 4.212 & .589 & .843 & .833 & .892 \\
F3 & 3.745 & .852 & .896 & .783 & \\
O1 & 8.439 & 4.903 & .478 & .734 & \\
O2 & 9.036 & 4.434 & .655 & .670 & \\
O3 & 9.650 & 5.197 & .464 & .738 & .760 \\
O4 & 10.271 & 5.153 & .573 & .709 & \\
O5 & 8.653 & 4.228 & .520 & .730 & \\
D1 & 7.12 & 3.031 & .592 & 0.663 & \\
D2 & 7.20 & 3.248 & .583 & 0.676 & .755 \\
D3 & 7.03 & 2.865 & .582 & 0.678 & \\
\hline
\end{tabular}

\section{Confirmatory factor analysis}

In this paper, the three indicators of specialized farmers cooperatives' financial activity capacity which got from the exploratory factor analysis were further examined, confirming this division by confirmatory factor analysis, determining the structure validity of the index system, providing the basis for model tests. In this paper, using AMOS19.0 to analyze the fitting results which are shown in Table 3.

Table 3. Confirmatory factor analysis results of cooperatives’ financial activity ability

\begin{tabular}{|c|c|c|c|c|}
\hline path & Estimate & S.E. & C.R. & $\mathrm{P}$ \\
\hline F3<---F & 1.000 & & & \\
\hline $\mathrm{F} 2<---\mathrm{F}$ & 1.457 & .110 & 13.235 & $* * *$ \\
\hline $\mathrm{F} 1<---\mathrm{F}$ & 1.742 & .114 & 15.280 & $* * *$ \\
\hline D3<---D & 1.000 & & & \\
\hline $\mathrm{D} 2<---\mathrm{D}$ & 1.698 & .224 & 7.570 & $* *$ \\
\hline D1<---D & 1.345 & .155 & 8.671 & $* *$ \\
\hline O3<---O & 1.000 & & & \\
\hline $\mathrm{O} 2<---\mathrm{O}$ & 1.853 & .248 & 7.462 & $* * *$ \\
\hline O1<---O & .669 & .065 & 10.272 & $* * *$ \\
\hline O4<---O & 1.468 & .207 & 7.093 & $* * *$ \\
\hline O5<---O & .649 & .124 & 5.239 & $* * *$ \\
\hline$\chi^{2}$ & & & & 0.915 \\
\hline df & & & & 0.932 \\
\hline$\chi^{2} / d f$ & & & & 0.024 \\
\hline
\end{tabular}

Note: $* * *$ said significance level $(\mathrm{p}<0.001), * *$ indicates significant level $(\mathrm{p}<0.01)$.

Fitting results show that, $\chi^{2}$ is 75.029 (degree of freedom $=44$ ), $\chi^{2} / d f$ is 1.705 , less than $2, \mathrm{P}$ is 0.002. At the same time, CFI and TLI are greater than 0.9 and closed to 1 . RMSEA is 0.024 . The path coefficients' corresponding CR values in measurement equation are greater than the reference value, and path coefficients have statistical significance ( $p<0.001$ or $p<0.01$ ). Synthesize the above results, using AMOS19.0 to calculate, the load factors coefficient matrix is shown in the Table 4, standardized estimate results are shown in Fig.1. Specialized farmers cooperatives' financing ability index factor loading value is reasonable and significant at the $1 \%$ level, showing that specialized farmers cooperatives' financing ability evaluation index system has good convergence. Factors through the tests on discrimination validity, showing that each factor not only can measure the different aspects of the farmers cooperatives' financing ability independently, but also can measure the same content of farmers cooperatives' financing ability, and there may be a higher-order factor. 
Using SPSS18.0 to calculate the correlation coefficient (0.920) which illustrates that the above method of calculation about financing ability, capital operation ability and suitability of the income distribution is feasible. This is also the validation of the related research results in this paper, which shows that model fitting is very well.

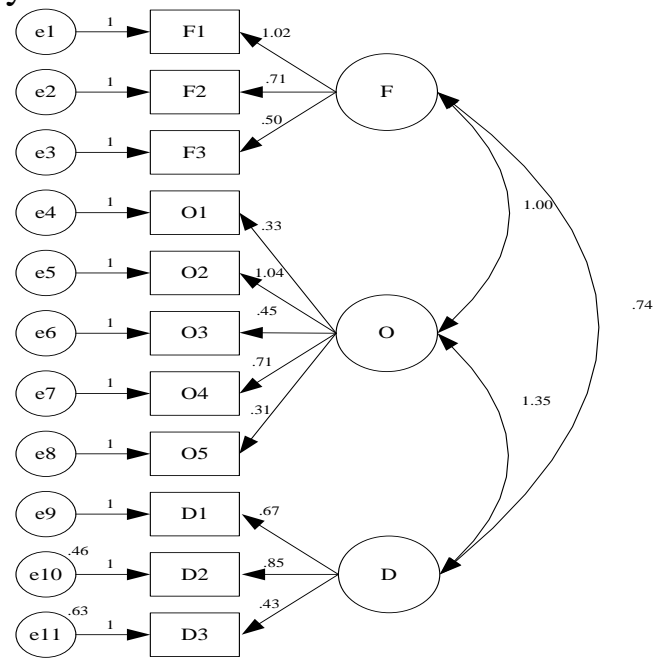

Fig.1 Confirmatory factor analysis of farmer's cooperatives' financial activity ability Table 4 Factor loading matrix of specialized farmers cooperatives' financial activity ability

\begin{tabular}{cccccc}
\hline path & Estimate & path & Estimate & path & Estimate \\
\hline F3<---F & 1.017 & D1<---D & .666 & O5<---O & .307 \\
F2<---F & .709 & O3<---O & .446 & $\mathrm{~F}<--->\mathrm{O}$ & .995 \\
F1<---F & .504 & $\mathrm{O} 2<---\mathrm{O}$ & 1.35 & $\mathrm{D}<--->\mathrm{O}$ & 1.345 \\
D3<---D & .425 & $\mathrm{O} 1<---\mathrm{O}$ & .327 & $\mathrm{D}<--->\mathrm{F}$ & .744 \\
D2<---D & .845 & $\mathrm{O} 4<---\mathrm{O}$ & .710 & & \\
\hline
\end{tabular}

The results show that the factor structure of specialized farmer's cooperatives' financial activity ability was tested, and specialized farmers cooperatives' financial activities can be divided into three parts, namely financing ability, working capital operation ability and income distribution fits. The empirical research based on the three parts is reliable.

\section{A second-order factor model test}

In order to simplify the model, this paper further builds the second-order factor of structural equation model based on the above research, and analyzes the structural equation model fitting using AMOS19.0. The results are shown in Fig.2.

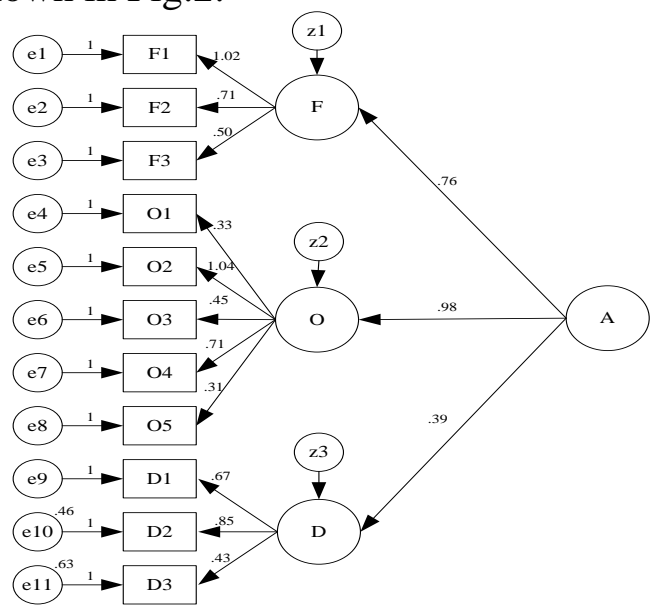

Fig. 2 Fitting results of second-order factor structure equation model 
Table 5 Fitness of structural equation model

\begin{tabular}{cccccc}
\hline Fitting index & Results & Reference & Fitting index & Results & Reference \\
\hline$\chi^{2} / d f$ & 1.803 & Less than 3 best & RFI & 0.652 & Close to 1 good \\
RMR & 0.046 & $>0.08$ & IFI & 0.898 & $>0.9$ \\
GFI & 0.886 & $>0.9$ & TLI & 0.908 & $>0.9$ \\
AGFI & 0.927 & $>0.9$ & CFI & 0.950 & $>0.9$ \\
PGFI & 0.512 & $>0.5$ & RMSEA & 0.132 & $>0.5$ \\
NFI & 0.928 & $>0.9$ & & & \\
\hline
\end{tabular}

Listed in Table 6 are the second-order factor of structural equation model fitting results of absolute fitting effect indicators, relative fitting effect indicators, alternative indicators and simple indicators, and most of indicators are in the range of reference and through the test. GFI value of 0.886 , IFI value of 0.898 , although do not reach the optimal value of 0.9 , are very close and can be accept. In addition, through the CMIN model fitting summary can be seen that the minimum sample differences CMIN is 77.521, greater than 0.5 , the relative chi-square CMIN/DF is 1.803 , less than 2 .There are no negative measurement errors, and the measurement errors are significant. Composite reliability of latent variables (C.R.) above 0.7 indicating good reliability composition. We can determine that goodness-of-fit index is ideal based on the above statistics.

Table 6 Path analysis results of structural equation model

\begin{tabular}{ccccc}
\hline Path & Estimate & S.E. & C.R. & P \\
\hline O <---A & 1.000 & & & \\
F $<---$ A & 1.000 & & & \\
D<---A & 1.000 & & & \\
F3<---F & 1.000 & .114 & 12.763 & $* * *$ \\
F2<---F & 1.455 & .112 & 15.598 & $* * *$ \\
F1<---F & 1.747 & & & \\
D3<---D & 1.000 & .219 & 7.731 & $* *$ \\
D2<---D & 1.693 & .157 & 8.592 & $* *$ \\
D1<---D & 1.349 & & & $* * *$ \\
O3<---O & 1.000 & .246 & 7.524 & $* * *$ \\
O2<---O & 1.851 & .063 & 10.619 & $* * *$ \\
O1<---O & .669 & .208 & 7.053 & $* * *$ \\
O4<---O & 1.467 & .124 & 5.226 & \\
O5<---O & .648 & & & \\
\hline
\end{tabular}

Note: $* * *$ said significance level $(\mathrm{p}<0.001), * *$ indicates significant level $(\mathrm{p}<0.01)$.

As can be seen from the fitting results, working capital operation capacity makes decisive effect for specialized farmer's cooperatives, financing ability is the second and income distribution fits are the lowest. Compared with the traditional factor analysis, the second-order factor model can more truly reflect the intrinsic link among indicators of specialized farmers cooperatives' financial activity ability, structural equation model allows the existence of index measurement error, the influence of the traditional factor analysis can't control other variables, and there are different levels of information loss when extracting total factor, and the structural equation model is more accurate than the obtained factor loading.

\section{Specialized farmers cooperatives' financial activity ability evaluation}

Weight. To determine weight of index system in this article by using correlation weight method, which is to determine the weight according to the correlation coefficient, and the method through a large number of sample data for related data test between variables. Correlation coefficient in Structural equation model is essentially standardization factor loading, and through the factor loading normalization processing could get indexes weights. After measuring, financing ability, operating ability and income distribution ability and related evaluation index's weight can be seen in Table 7. 
Table 7.Evaluation indicator system

\begin{tabular}{cccc}
\hline Rule layer & Index layer & Index code & Index weight \\
\hline Financing ability & Basic ability & F1 & 0.435 \\
F & Development potential & F2 & 0.343 \\
0.357 & Support & F3 & 0.222 \\
& Group size & O1 & 0.117 \\
Investment operation ability & Operating activities & O2 & 0.366 \\
O & Investment in science and technology & O3 & 0.157 \\
0.46 & Membership benefits & O4 & 0.250 \\
& Social influence & O5 & 0.109 \\
Income distribution & Decision-making process & D1 & 0.319 \\
D & Implementation process & D2 & 0.456 \\
0.183 & Effect of distribution & D3 & 0.225 \\
\hline
\end{tabular}

Measuring specialized farmers cooperatives' financial activities ability. By the calculation, specialized farmers cooperatives' financial activities ability evaluation results are shown in Table 8.

Table 8 Evaluation result of specialized farmers cooperatives' financial activities ability

\begin{tabular}{ccccccccc}
\hline $\begin{array}{c}\text { Organization } \\
\text { name }\end{array}$ & Score & Ranking & $\begin{array}{c}\text { Organization } \\
\text { name }\end{array}$ & Score & Ranking & $\begin{array}{c}\text { Organization } \\
\text { name }\end{array}$ & Score & Ranking \\
\hline XD & 3.4342 & 1 & HR & 2.8215 & 17 & ZX & 2.4033 & 33 \\
MH & 3.1355 & 2 & ZO & 2.8009 & 18 & FX & 2.3954 & 34 \\
HS & 3.0852 & 3 & WQ & 2.7922 & 19 & ZL & 2.3917 & 35 \\
TC & 3.0755 & 4 & YY & 2.7754 & 20 & YC & 2.3528 & 36 \\
CL & 3.0416 & 5 & SX & 2.7680 & 21 & ZJ & 2.3126 & 37 \\
QF & 2.9695 & 6 & SF & 2.7552 & 22 & WJ & 2.3097 & 38 \\
CH & 2.9653 & 7 & LY & 2.7099 & 23 & LF & 2.3047 & 39 \\
FY & 2.9653 & 8 & HX & 2.6936 & 24 & TR & 2.2776 & 40 \\
HO & 2.9582 & 9 & JF & 2.6844 & 25 & FA & 2.2227 & 41 \\
WY & 2.9368 & 10 & CQ & 2.6834 & 26 & YX & 2.1241 & 42 \\
LD & 2.9082 & 11 & JR & 2.5848 & 27 & SG & 2.1184 & 43 \\
QA & 2.8730 & 12 & XY & 2.5245 & 28 & GY & 2.0497 & 44 \\
XZ & 2.8650 & 13 & LC & 2.4905 & 29 & GZ & 2.0427 & 45 \\
QZ & 2.8646 & 14 & JG & 2.4731 & 30 & LS & 1.9922 & 46 \\
NY & 2.8323 & 15 & SN & 2.4442 & 31 & BG & 1.7021 & 47 \\
TH & 2.8260 & 16 & JB & 2.4292 & 32 & & & \\
\hline
\end{tabular}

Analysis of the results. As can be seen from comprehensive evaluation of the financial activities ability: 1 .The top-rated cooperatives whose three kinds of ability coordinate with each other and relatively high. Such as XD (Xin Ding fruit and vegetable farming co-operatives), working capital score of 3.4467, ranking first, income distribution fit evaluation score of 4.1293, ranking second, financing ability score of 2.024, ranking twenty-fifth. It shows that only the three ability develop coordinately can cooperatives make greater progress. 2 . The ability to play a leading role in three is investment capital operation ability mostly, for example, XD, the total ranking first, capital operation ability score of 3.4467, the investment in science and technology ability is particularly outstanding score of 4.51, ranking first, membership benefits score of 3.8622, ranking third.3. Most cooperatives which have strong comprehensive ability is established earlier, managed normally, and operated with a large scale, such as XD whose registered capital of 2 million yuan, 2.3 million yuan in fixed assets, turnover in 2012 of 3.15 million yuan.

Therefore, specialized farmers cooperatives' financing structure, income distribution and value creation is a united and indivisible organic. Financing structure determines the income distribution system, while the distribution of income in turn affects the financing structure, financing structure and income distribution system jointly determine whether the cooperatives can have the necessary funding supply, whether there is sufficient room for value creation. Only the more value created can it ensure the distribution. So from the perspective of harmony, it is crucial to study how to coordinate the three. Projects of Hebei province science and technology plans, 14457509D. 


\section{References}

[1] Zimin Liu, Dan Yang. Efficiency Evaluation of Vegetable Specialized Cooperatives Based on Data of Chongqing Municipality [J]. Asian Agricultural Research, 2014, 02:73-76.

[2] Xiuying Li,Yidan Zhang,Yanhui Liu,Xiujie Zu. Status Quo and Problems of Fishery Cooperatives in Jilin Province and Countermeasures[J].Asian Agricultural Research,2013,07:73-75.

[3] Huide Huang, Wan Zhen Zhang, Enping LIU. Development and Economic Effect of Farmers' Specialized Cooperatives [J]. Asian Agricultural Research, 2013, 02:55-57.

[4] Xiyun Ni. Research on development capacity of specialized farmer's cooperatives [D]. Northwest Agriculture \& Forestry University.2012. 